\title{
A new multi-genomic approach for the study of biogeochemical cycles at global
} scale: the molecular reconstruction of the sulfur cycle

Valerie De Anda ${ }^{1 *}$, Icoquih Zapata-Peñasco ${ }^{2}$, Bruno Contreras-Moreira ${ }^{3,4}$, Augusto Cesar Poot-Hernandez ${ }^{5}$ Luis E. Eguiarte ${ }^{1}$ and Valeria Souza ${ }^{1 * *}$

${ }^{I}$ Departamento de Ecología Evolutiva, Instituto de Ecología, Universidad Nacional Autónoma de México, 70-275, México D.F. 04510

${ }^{2}$ Dirección de Investigación en Transformación de Hidrocarburos. Instituto Mexicano del Petróleo, Eje Central Lázaro Cárdenas, Norte 152, Col. San Bartolo Atepehuacan, 07730, México

${ }^{3}$ Estación Experimental de Aula Dei, Consejo Superior de Investigaciones Científicas (EEAD-CSIC), Avda. Montañana, 1005, Zaragoza 50059, Spain

${ }^{4}$ Fundación ARAID, calle María de Luna 11, 50018 Zaragoza, Spain.

${ }^{5}$ Departamento de Ingeniería Celular y Biocatálisis, Instituto de Biotecnología, Universidad Nacional Autónoma de México, Cuernavaca, Morelos 62210, México

For correspondence.*E-mail valdeanda@ciencias.unam.mx **E-mail souza@unam.mx; Tel.925 423 2284; Fax 9254223160.

\section{Summary}

Despite the great advances in microbial ecology and the explosion of high throughput sequencing, our ability to understand and integrate the global biogeochemical cycles is still limited. Here we propose a novel approach to summarize the complexity of the Sulfur cycle based on the minimum ecosystem concept, the microbial mat model and the relative entropy of protein domains involved in S-metabolism. This methodology produces a single value, called the Sulfur Score (SS), which informs about the specific S-related molecular machinery. After curating an inventory of microorganisms, pathways and genes taking part in this cycle, we benchmark the performance of the SS on a collection of 2,107 nonredundant RefSeq genomes, 900 metagenomes from MG-RAST and 35 metagenomes analyzed for the first time. We find that the SS is able to correctly classify microorganisms known to be involved in the S-cycle, yielding an Area Under the ROC Curve of 0.985. Moreover, when sorting environments the top-scoring metagenomes were hydrothermal vents, microbial mats and deep-sea sediments, among others. This methodology can be generalized to the analysis of other biogeochemical cycles or processes. Provided that an inventory of relevant pathways and microorganisms can be compiled, entropy-based scores 
could be used to detect environmental patterns and informative samples in multi-genomic scale.

\section{INTRODUCTION}

Despite their fundamental importance in sustaining life on Earth, understanding the fluxes of fundamental elements (C, H, O, N, S, and P) through the Earth's surface has been challenging for several reasons (Li et al., 2012; Newman and Banfield, 2002). First, the global biogeochemical cycles are enormously complex as they are an interconnected network of biological, chemical and geophysical processes that have been coevolving in the biosphere since the apparition of the first metabolic processes on Earth ( $\sim 3.8$ billion years ago) (Falkowski et al., 2008). Since then, the evolutionary history of life on Earth has been shaped by a complex synergistic cooperation of multispecies assemblages that differ in terms of ecological and metabolic capabilities (Canfield 2005). Secondly, although these assemblages are often spatially and temporally separated, they effectively couple electron transfer (i.e., redox) reactions that transform elements and energy derived from several abiotic processes (Falkowski et al., 2008). Thirdly, these abiotic processes involve the continuous supply and removal of elements from various Earth surface reservoirs, such as geothermal processes derived from mantle and crust, tectonics and rock weathering, and photochemical processes in the atmosphere including the constant flux of solar energy (Hedges, 1992).

As a result of these challenges, the fluxes of fundamental atoms through Earth have been studied and approached using different disciplines that address specific layers of complexity. For instance, geochemistry and atmospheric sciences have been focused on addressing the major abiotic process at global planetary scales, i.e., processes influencing the flux of elements to and from the various Earth surface reservoirs and atmosphere (Canfield et al., 2005, Falkowski et al., 2008).

Moreover, microbial ecology has emphasized in understanding the links between microbial catalyzed activities and ecosystem and biogeochemical processes (Morales and Holben, 2011). Current approaches for establishing metabolic relationships in situ are based on targeting coding-sequences involved in specific biochemical pathways related to carbon, nitrogen, sulfur, and phosphorus cycling. In this way, DNA or RNA extracted directly from 
67

68

69

70

71

72

73

74

75

76

77

78

natural environments is sequenced and quantified with conventional PCR and Sanger sequencing or microarray analyses (Loy et al., 2004; Khodadad and Foster, 2012) for example the GeoChip (Tu et al., 2014); or other 'omics' techniques such as metagenomics (Quaiser et al., 2011; Swingley et al., 2012; Llorens-Marès et al., 2015) or metatranscriptomics (Stewart et al., 2011; Chen et al., 2015).

However, despite the great advances in microbial ecology and high throughput sequencing, our ability to understand and integrate the global biogeochemical cycles is still limited. Here, we propose a new comprehensive approach to evaluate, compare, and facilitate the study of such cycles based on the metabolic machinery of the microorganisms responsible for driving element fluxes throughout the Earth. The approach is based mainly on three aspects: i) the minimum ecosystem concept: which considers the properties, forces (outside energy), flow pathways (energy and matter), interactions, and feedback loops or circuits for the flow of matter or energy (Odum,1993); ii) the microbial mats, which are nearly closed and selfsustaining ecosystems that comprise the major biogeochemical cycles, trophic levels and food webs in a vertical laminate pattern (Bolhuis et al., 2014); and iii) the mathematical rationalization of Kullback-Leibler divergence, also known as relative entropy $H^{\prime}$ (Kullback and Leibler, 1951). Relative entropy has been widely applied in physics, communication theory and statistical inference, and is interpreted as a measure of disorder, information and uncertainty, respectively (Commenges, 2015). Here we use the communication theory concept of H' to summarize the information conveyed by the protein domains (metabolic machinery) encoded by environmental DNA sequences. The application of this measure in biology was originally developed by Stormo and colleagues to identify binding sites that regulate gene transcription sites (Hertz and Stormo, 1999).

In this context, the compartmentalization of microbial mats provides clear, natural or arbitrary boundaries that evoke the concept of "minimum ecosystem", which can be delimited in a natural or arbitrary sense (Odum, 1993). Therefore, specific parts of the cycle may be seen as parts of a whole. For instance, the redox level, reduced-oxidized compounds or even genes and enzymes implicated in certain routes can be used as ecosystem boundaries. These assemblies set up a unit that represents the minimum ecosystem with the minimum requirements to be functional, therefore this can be applied to measure the information derived from the complexity inside any biogeochemical cycle. 
To test and evaluate the performance of our conceptualization, we focused on the biogeochemical Sulfur cycle (from now on S-cycle), due to its critical role in the biogeochemistry of the planet - i.e., respiration of sedimentary organic matter, oxidation state of the atmosphere and oceans, and the composition of seawater (Halevy et al., 2012). Despite the extensive biochemical knowledge of both oxidative and reductive microorganisms (Rabus et al., 2013; Canfield, 2015; Dahl, 2017), there are no studies aiming to integrate all the microbiological and geochemical transformations and their corresponding metabolic pathways of the sulfur cycle. Our study proposes a general computational approach that can be easily modified and used to compare and measure other biogeochemical cycles. This procedure generates measurable scores to evaluate these cycles and their importance and ecological weight on a global scale.

\section{MATERIALS AND METHODS}

The computational analysis addressing the different levels of complexity of the S-cycle was divided into four stages illustrated in Figure 1. The corresponding scripts and documentation are available for download from: https://github.com/eead-csic-compbio/metagenome_Pfam_score.

\section{STAGE 1: The biogeochemical complexity of S-cycle and 'omic'-datasets.}

\section{Taxonomic representatives of sulfur cycle: the microbial mat model. According to the} minimum ecosystem concept, we consider microbial mats as models of a minimum ecological system (Microbial Mat Model). Based on the metabolic guilds found in microbial mats and other S-derived environments (i.e., hot springs, black smokers, sludge, etc.), we reviewed primary literature and the MetaCyc database (Caspi et al., 2012) to select S-based microorganisms (at genus or species level) with experimental evidence of the physiology of degradation, reduction, oxidation, or disproportionation of organic/inorganic S-compounds. The list of S-based prokaryotes is found in Table S1. The non-redundant list of these S-based microorganisms with fully sequenced genomes (December 2016) was called the Sulfur list (Suli), which currently contains 161 genomes used as input of the pipeline.

Random taxonomic representatives (RList): In order to build negative control sets of organisms that are not particularly enriched on metabolic preferences, 1,000 random lists of 
129

130

131

132

133

134

135

136

137

138

139

140

141

142

143

144

145

146

147

148

149

150

151

152

153

154

155

156

157

158

159 microorganisms were drawn using the genomic dataset explained below as reference, with the same number of microorganisms included in Suli.

Metabolic pathways and genes: We gathered and classified the metabolic pathways involved in the S-cycle from the primary literature and expert-curated databases KEGG (Kanehisa and Goto, 2000) and MetaCyc (Caspi et al., 2012). This molecular information was integrated into

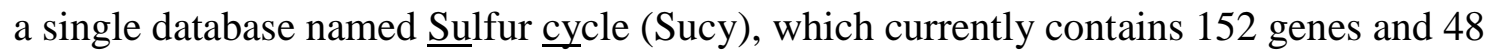
enzyme classification numbers annotated in the Enzyme classification (http://enzyme.expasy.org) (Table S2). The 152 FASTA sequences of the peptides encoded by these genes were downloaded from UniProt (Magrane and Consortium, 2011) and used as the input of the pipeline.

Omic datasets. In order to test, compare and evaluate the importance of the S-cycle in 'omic' datasets, we generated the following databases:

i) Genomic dataset (Gen): Due to the redundancy of complete genomes deposited in RefSeq (https://www.ncbi.nlm.nih.gov/genome/browse/reference; 4,158 genomes at the time of the analysis, December 21, 2016), we decided to reduce the set of genomic data by using a web-based tool, that uses "genomic similarity scores" (Moreno-Hagelsieb et al., 2013).

Selecting values of genomic similarity of 0.95 and a DNA signature of 0.01 , we obtained a total of 2,107 non-redundant genomes in FASTA format.

ii) Metagenomic dataset (Met): We selected metagenomes from the MG-RAST server version 3.6 that met the following conditions: i) publicly available; ii) metadata associated; and iii) environmental samples (isolated from defined environments o features like rivers, soil, biofilms), discarding microbiome host-associated metagenomes (i.e., to human, cow, chicken). In addition, we also included 35 unpublished metagenomes derived from sediment, water and microbial mats from Cuatro Ciénegas (Coahuila, Mexico), which were also submitted to the MG-RAST pipeline.

Using the above-mentioned conditions, a total of 935 metagenomes were downloaded in FASTA format (http://api.metagenomics.anl.gov/api.html, coding regions within the reads, December, 2016). Then, we measured the Mean Size Length (MSL) of the peptide coding regions of the Met FASTA files (Figure S1A). Taking into account that the 152 sulfur proteins 
160

161

162

163

164

165

166

167

168

169

170

171

172

173

174

175

176

177

178

179

180

181

182

183

184

185

186

187

188

189

(Sucy) have lengths ranging from 49 to 1,020 amino acid residues (aa), their detection in metagenomic samples will likely be affected by MSL (Figure S1B). For example, the identification of long proteins harboring several domains (i.e., catalytic, cofactor binding etc.) might be impaired in metagenomes with short MSL.

iii) Fragmented genomic dataset (GenF). We used the genomic dataset as a reference for benchmarking the detection limits of the protein families. The peptide FASTA-format files of the 2,107 non-redundant genomes were in silico sheared into seven categories of increasing fragment length, taking into account the variation in read sizes of the metagenomic dataset (Figure S1A).

\section{STAGE 2: Domain composition of the sulfur proteins}

We used Interproscan 5.21-60.0 (Jones et al., 2014) to annotate the protein domains encoded in the 152 Sucy genes, according to the Pfam-A database v30 (Finn et al., 2008). In total, 112 Pfam domains where identified and subsequently scanned against the 'omic' datasets with HMMER 3.0 (Finn et al., 2011).

\section{STAGE 3: Relative entropy and its use to detect informative sulfur-related protein}

\section{domains}

In order to obtain an estimate of how protein families are represented in S-based

microorganisms, we used a derivative of the Kullback-Leibler divergence (Kullback and Leibler, 1951) - also known as relative entropy $H^{\prime}(i)$ - to measure the difference between probabilities $P$ and $Q$ (see Eq. 1 below). In this context, $P(i)$ represents the frequency of protein domain $i$ in Suli genomes (observed frequency), while $Q(i)$ represents the frequency in the complete genomic dataset (expected frequency). $H^{\prime}$, in bits, captures the extent to which a domain informs specifically about sulfur metabolism. $H^{\prime}$ values that are close to 1 correspond to the most informative Pfam domains (enriched among S-based genomes), whereas low $H^{\prime}$ values (close to zero) describe non-informative ones. Negative values correspond to proteins observed less than expected. 
190

191

192

193

194

195

196

197

198

199

200

201

202

203

204

205

206

207

208

209

210

211

212

213

214

215

216

217

As a control, $H^{\prime}$ was recalculated both in Gen and GenF datasets replacing Suli with 1,000 equally sized lists of random-sampled genomes (Rlist). Using these procedures, we evaluated the variation of relative entropy of each Pfam domain in order to i) short-list those that could be used as markers in metagenomic dataset (regardless of their MSL) and ii) to generate a score which could be used to compare the importance of S-metabolism in 'omic'-samples (either in Gen or Met).

Clustering of Pfam domains according to their entropy: The following clustering algorithms were tested: K-Means, Affinity propagation, Mean-shift Spectral, Ward hierarchical, Agglomerative, DBSCAN and Birch. These methods are part of the scikit-learn Machine Learning Python module (http://scikit-learn.org/stable/modules/clustering.html).

\section{STAGE 4: The Sulfur Score (SS): origin, interpretation, properties and benchmark}

We propose to evaluate the importance of biogeochemical S-cycle in 'omic'-datasets using a single metric that we call "Sulfur Score" (SS) (Eq. 2). By this approach, sulfur informative protein domains would contribute to higher SS, whereas non-informative ones would decrease it. This is an extension of procedures originally developed for the alignment of DNA and protein motifs, in which individual positions are independent and additive, and can be simply summed up to obtain the total weight or information content (Hertz and Stormo, 1999). Instead of aligning sequences, in our context we compare a presence/absence string of Pfam domains, from which a total weight $(S S)$ is computed.

$$
\boldsymbol{S S}=\sum_{i=1}^{112} \boldsymbol{H}^{\prime}
$$

Eq. 2

If we compare total $S S$ across several genomes or environments, those in which the majority of metabolic pathways of S-cycle are represented will thus have a high SS; in contrast, low SS values should be expected if proteins involved in the S-cycle are not particularly enriched. 
Calibration: We took into account the MSL of each metagenome to compute the SS. Briefly; we gathered the entropy values $\left(H^{\prime}\right)$ of the 112 Pfams in Gen and GenF (Figure S2A). $H^{\prime}$ estimates vary among the different GenF categories, with the major differences observed for fragments of 30 and 60 aa (Figure S2B) and estimates converging with increasing MSL. Therefore, the $S S$ algorithm considers the MSL of the 'omic'-sample and chooses the appropriate baseline $H^{\prime}$ 'values pre-computed on the GenF dataset. The GenF fragment size ranges $(30,60,100,150,200,250$ and 300) match the observed MSL in real metagenomic sets (see Figure S1).

Properties and performance of SS: Because the outcome of the SS depends on i) the list of Srelated Pfam domains and ii) the curated list of S-genomes, we measured its reproducibility with several approaches. First, scores computed in 2014 (Pfam v27, 1528 non-redundant genomes, 156 species in Suli) were compared to the current results (Pfam v30, 2017 nonredundant genomes, 161 curated species in Suli). Second, we compared the outcomes of the SS using a random sampling experiment. Briefly, we computed SS 1000 times both in the Gen and the Met datasets sorted in terms of their GenF size category. In each test, $\approx 50 \%$ of the $112 \mathrm{~S}$ related Pfam domains were randomly selected to compute SS. Finally, we benchmarked the predictive capacity of the $S S$ in order to accurately classify the genomes of S-related organisms (Suli, $\mathrm{n}=161$, positive instances) in contrast with a larger set of non-redundant genomes (Gen Suli, n=1.946, negative instances). True Positive Rates (TPR), False Positive Rates (FPR) and the resulting of Receiver Operating Characteristic (ROC) plots were produced with the scikitlearn module (http://scikit-learn.org/stable/modules/model_evaluation.html), and finally the Area Under the ROC Curve (AUC) was computed.

\section{RESULTS AND DISCUSSION}

\section{Defining the biogeochemical S-cycle}

What parameters define a biogeochemical cycle, and what are its limits and scope? Which elements should be considered necessary for each cycle? The study of element fluxes between rocks, atmosphere, oceans and biological activity can be extremely complex in terms of space and time, ranging from single living cells to entire ecosystems, and can be completed in microseconds or instead developed over geological time scales (Hedges, 1992; Falkowski et 
al., 2008; Zhao et al., 2014; Olson et al., 2016; Widder et al., 2016). Currently, microbial ecology techniques are insufficient to capture the integral complexity of the biogeochemical cycles by selecting a few marker genes to evaluate the importance of any given element in the environment. Here, we argue that a comprehensive description of the relationship between complex biotic an abiotic process is crucial to describe and understand the importance of global biogeochemical cycles and provide a method to do so by taking advantage of 'omic'-era data.

We propose a new approach to analyze, compare, evaluate and quantify the importance of biogeochemical cycles in 'omic' datasets summarized in Figure 1, focusing, as a case-study, on the S-cycle. The first step consists on the systematic acquisition of the molecular and ecological information required to describe the cycle of interest. This information can be considered an inventory (Odum, 1993).

With the manual curation effort, we obtained both: a list of microorganisms (Suli), and a list of genes encoding enzymes (Sucy) related to the S-cycle. The Suli list includes the microorganisms involved in the global S-cycle using the microbial mats as ecological model. Microbial mats are compartmentalized organizations that were the first ecosystems to appear on Earth and have evolved over more than three billion years into the complex ecosystems that we know today (Herman EK and Kump LR, 2005). Functionally, microbial mats are self-sufficient structures that support most of the major biogeochemical cycles within a vertical dimension of only a few millimeters in a multilayer space (Pinckney and Paerl, 1997) (Figure 2A). These assemblies represent ecosystems with the minimum requirements to be functional and therefore can be used to explore the complexity of biogeochemical cycles. In contrast with the compact nature of microbial mats, the distribution of the metabolic S-guilds is widely dispersed at planetary scale, being found in rivers and estuaries, lagoons, oceans, sediments and deep hydrothermal vents (Halevy et al., 2012).

The distribution of S-related bacterial taxa can be analyzed in terms of redox potential and Gibbs Energy of Free Formation of S-compounds, resembling the compact layout of the metabolic guilds in the microbial mat (Figure 2B). Therefore, Suli includes three main groups of microorganisms belonging to the $\mathrm{S}$-metabolic guilds in microbial mats i) chemolithotrophic color less sulfur bacteria (CLSB), ii) anaerobic phototrophs: purple sulfur bacteria (PSB), green sulfur bacteria, (GSB), and iii) sulfate reducing bacteria (SRB) as well as deep-branch sulfur 
279 hyperthermophile microorganisms found in extreme conditions (hot springs, black smokers, 280 etc.), such as elemental sulfur reducing (SRM) and oxidizer (SO) microorganisms.

The other manually curated list of the inventory, Sucy, contains the metabolic pathways, 282 genes and enzyme activity numbers involved in the S-fluxes (Table S2). To the best of our knowledge, this is the first attempt to integrate the biotic and abiotic processes involved in the mobilization of inorganic/organic S-compounds through microbial-catalyzed reactions at global scale; we gathered and classified all the metabolic pathways involved in the S-cycle according to three key aspects described in Figure 2B, i) S-compound: either organic or inorganic, derived from abiotic or biotic processes, ii) standard Gibbs free energy of formation (GFEF), and iii) metabolic role of the S-compound. The metabolic pathways involved in these S-compounds were systematically divided into 28 pathways (Table S3). We included the pathways involved in a) the oxidation/reduction of inorganic S-compounds, used as source of energy, electron donor or acceptor, b) the degradation of organic S-compounds such as aliphatic sulfonates sulfur amino acids, and organosulfonates, c) methanogenesis from methylated thiols such dimethyl sulfide DMS, metylthio-propanoate and methanethiol, which are generated in nature by different biogeochemical processes (Caspi et al., 2012), and d) the biosynthesis of sulfolipids (SQDG), because it has been observed that some bacteria living in S-rich and Placking environments, are able to synthetized sulfolipids instead of phospholipids in the membrane as an adaptation of the selective pressures of the environment (Alcaraz et al., 2008). metabolic complexes), we linked all the enzymatic steps and S-compounds into a 300 comprehensive representation of the S-cycle in a single cell (Figure 3), with the following 301 features i) the comprehensive interconnection of pathways in terms of energy flow, ii) the 302 direction of the reactions of the important biogeochemical S-compounds, iii) the interplay of 303 the redox gradient (organic/inorganic) of the intermediate compounds that act as key axes of organic and inorganic reactions (i.e., sulfite), and iv) the molecular reconstruction of S-cycle at different levels (genes, abiotic sulfur-derived compounds and enzymatic steps). data in both genome and metagenome databases. We also included 35 unpublished metagenomes derived from microbial mats, water and sediment from an ultra-oligotrophic 
shallow lake in Cuatro Cienegas, Coahuila (CCC), Mexico. Altogether, these 935 metagenomes set up the Met dataset. The Gen dataset was sheared with different fragment sizes taking into account the Mean Size Length (MSL) of Met (Figure S1), producing dataset GenF, which was used for estimating the detection limits of sulfur protein families. We describe the computation approach step-by-step below.

\section{Relative entropy as a way to identify protein domains that inform about the S-cycle}

After the first step of collecting the datasets, the second step involved the annotation of the coding sequences of the 152 genes in Sucy, yielding a total of 112 Pfam domains (Pfam Sucy in Figure 1). The third step consisted in measuring the relative entropy ( $\left.H^{\prime}\right)$ of each Pfam using Equation 1. The presence of each Pfam domain in Suli (genome list) and in the genomic datasets (Gen and GenF) was used as observed and expected frequencies respectively. The obtained $H^{\prime}$ values are shown in Figure S2.

As negative control, we tested to what extent those $H^{\prime}$ values depend on the particular genomes curated in Suli. To do so, we replaced Suli by 1,000 lists of random-sampled genomes and used them to compute the observed frequencies. As expected, there was a clear difference between the $H^{\prime}$ computed using random genomes (Figure S3A), and those obtained with the manually curated list of S- based microorganisms (Figure S3B). In particular, entropy values derived from the random test were found to be approximately symmetric and consistently low among the GenF size categories, yielding values of -0.09 , and 0.1 as $5 \%$ and $95 \%$ percentiles, respectively (Table $\mathrm{S} 4$ ).

We then evaluated the behavior of the $H^{\prime}$ 'values in both Gen and GenF to test whether informative Pfam domains can be used as molecular markers of S-cycle in metagenomic sequences of variable MSL. In order to be considered as a marker gene, each Pfam domain had to fulfill three requirements 1) produce consistently high mean $H^{\prime}$ values in Gen and GenF, 2) display low standard deviation (std), and 3) obtain $H^{\prime}$ values clearly separated from the random distribution. We tested several clustering methods, summarized in Figure S4; among them, the Birch and Ward methods grouped together the informative protein domains with low std (Figure S5). However, Ward clustering included a few protein domains relevant in the S-cycle, which were otherwise discarded by the Birch method. Therefore, we selected the Ward method, which produced three clusters of protein domains described in Figure 4. 

those obtained in the negative control explained earlier. Cluster 1 identifies 12 Pfam domains

342 listed in Table 1, with high entropy and low std, and can therefore be proposed as molecular

343 markers. Among the proposed molecular marker protein domains are APS-Reductase

344 (PF12139: $\left.H^{\prime}=1.2\right)$, ATP-sulfurilase (PF01747: $\left.H^{\prime}=1.03\right)$ and DsrC (PF04358: $\left.H^{\prime}=0.52\right)$, key

345 protein families in metabolic pathways involved in both sulfur oxidation/reduction processes.

346 Finally, cluster 2 groups 6 domains (described in Table S5) with high entropy values and high

347 std, such as PUA-like domain (PF14306: $\left.H^{\prime}=1\right)$. We presume that the protein domains listed in

348 Table S5 are key players in S-metabolism and their presence in almost all complete-sequenced

349 S-associated microorganisms suggests their important roles.

350 Despite their different properties, all the 112 Pfam domains mentioned in those clusters were

351 subsequently used in the next sections to detect peptides related to the S-cycle in 'omic'

352 datasets.

Table 1 Informative Pfam domains with high H' and high std. Novel proposed molecular marker domains in metagenomic datasets of variable mean size length (MSL)

\begin{tabular}{|c|c|c|c|}
\hline $\begin{array}{l}\text { Pfam } \\
\text { ( Suli } \\
\text { ocurrences) }\end{array}$ & $\begin{array}{l}H^{\prime} \\
\text { mean }\end{array}$ & $\begin{array}{l}H^{\prime} \\
\text { std }\end{array}$ & Description \\
\hline $\begin{array}{l}\text { PF12139 } \\
58 / 161\end{array}$ & 1.2 & 0.01 & $\begin{array}{l}\text { Adenosine-5'-phosphosulfate reductase beta subunit: Key protein domain for both sulfur } \\
\text { oxidation/reduction metabolic pathways. Has been widely studied in the dissimilatory sulfate } \\
\text { reduction pathway. In all recognized sulfate-reducing prokaryotes, the dissimilatory process } \\
\text { is mediated by three key enzymes: Sat, Apr and Dsr. Homologous proteins are also present } \\
\text { in the anoxygenic photolithotrophic and chemolithotrophic sulfur-oxidizing bacteria (CLSB, } \\
\text { PSB, GSB), in different cluster organization (Meyer and Kuever, 2007). }\end{array}$ \\
\hline $\begin{array}{l}\text { PF00374 } \\
135 / 161\end{array}$ & 1.1 & 0.09 & $\begin{array}{l}\text { Nickel-dependent hydrogenase: Hydrogenases with S-cluster and selenium containing Cys- } \\
\mathrm{x} \text {-x-Cys motifs involved in the binding of nickel. Among the homologues of this hydrogenase } \\
\text { domain is the alpha subunit of the sulfhydrogenase I complex of Pyrococcus furiosus, that } \\
\text { catalyzes the reduction of polysulfide to hydrogen sulfide with NADPH as the electron donor } \\
\text { (Pedroni } \text { et al., 1995). }\end{array}$ \\
\hline $\begin{array}{l}\text { PF01747 } \\
103 / 161\end{array}$ & 1.03 & 0.06 & $\begin{array}{l}\text { ATP-sulfurylase: Key protein domain for both sulfur oxidation and reduction processes. The } \\
\text { enzyme catalyzes the transfer of the adenylyl group from ATP to inorganic sulfate, producing } \\
\text { adenosine 5'-phosphosulfate (APS) and pyrophosphate, or the reverse reaction (Taguchi et } \\
\text { al., 2004). }\end{array}$ \\
\hline $\begin{array}{l}\text { PF02662 } \\
62 / 161\end{array}$ & 0.82 & 0.03 & $\begin{array}{l}\text { Methyl-viologen-reducing hydrogenase, delta subunit: Is one of the enzymes involved in } \\
\text { methanogenesis and encoded in the mth-flp-mvh-mrt cluster of methane genes in } \\
\text { Methanothermobacter thermautotrophicus. No specific functions have been assigned to the } \\
\text { delta subunit (Finn et al., 2008). }\end{array}$ \\
\hline $\begin{array}{l}\text { PF10418 } \\
122 / 161\end{array}$ & 0.78 & 0.06 & $\begin{array}{l}\text { Iron-sulfur cluster binding domain of dihydroorotate dehydrogenase B: Among the } \\
\text { homologous genes in this family are asrA and asrB from Salmonella enterica enterica } \\
\text { serovar Typhimurium, which encode 1) a dissimilatory sulfite reductase, 2) a gamma subunit } \\
\text { of the sulfhydrogenase I complex of Pyrococcus furiosus and, 3) a gamma subunit of the } \\
\text { sulfhydrogenase II complex of the same organism (Caspi et al., 2012). }\end{array}$ \\
\hline
\end{tabular}




\begin{tabular}{|c|c|c|c|}
\hline $\begin{array}{l}\text { PF } 13247 \\
149 / 161\end{array}$ & 0.66 & 0.06 & $\begin{array}{l}\text { 4Fe-4S dicluster domain: Homologues of this family include: 1) DsrO, a ferredoxin-like } \\
\text { protein, related to the electron transfer subunits of respiratory enzymes, 2) dimethylsulfide } \\
\text { dehydrogenase } \beta \text { subunit (ddhB ), involved in dimethyl sulfide degradation in Rhodovulum } \\
\text { sulfidophilum and 3) sulfur reductase FeS subunit (sreB) of Acidianus ambivalens, involved } \\
\text { in the sulfur reduction using } \mathrm{H}_{2} \text { or organic substrates as electron donors (Caspi et al., 2012). }\end{array}$ \\
\hline $\begin{array}{l}\text { PF04358 } \\
73 / 161\end{array}$ & 0.52 & 0 & $\begin{array}{l}\text { DsrC like protein: DsrC is present in all organisms encoding a dsrAB sulfite reductase } \\
\text { (sulfate/sulfite reducers or sulfur oxidizers). The physiological studies suggest that sulfate } \\
\text { reduction rates are determined by cellular levels of this protein. The dissimilatory sulfate } \\
\text { reduction couples the four-electron reduction of the DsrC trisulfide to energy conservation } \\
\text { (Santos et al., 2015). DsrC was initially described as a subunit of DsrAB, forming a tight } \\
\text { complex; however, it is not a subunit, but rather a protein with which DsrAB interacts. DsrC } \\
\text { is involved in sulfur-transfer reactions; there is a disulfide bond between the two DsrC } \\
\text { cysteines as a redox-active center in the sulfite reduction pathway. Moreover, DsrC is among } \\
\text { the most highly expressed sulfur energy metabolism genes in isolated organisms and meta- } \\
\text { transcriptomes (Santos et al., 2015). }\end{array}$ \\
\hline $\begin{array}{l}\text { PF01058 } \\
158 / 161\end{array}$ & 0.45 & 0.01 & $\begin{array}{l}\text { NADH ubiquinone oxidoreductase, } 20 \text { Kd subunit: Homologous genes are found in the } \\
\text { delta subunits of both sulfhydrogenase complexes of Pyrococcus furiosus (Caspi et al., } \\
\text { 2012). }\end{array}$ \\
\hline $\begin{array}{l}\text { PF01568 } \\
156 / 161\end{array}$ & 0.4 & 0.05 & $\begin{array}{l}\text { Molydopterin dinucleotide binding domain: This domain corresponds to the C-terminal } \\
\text { domain IV in dimethyl sulfoxide (DMSO) reductase (Finn et al., 2008). }\end{array}$ \\
\hline $\begin{array}{l}\text { PF09242 } \\
39 / 161\end{array}$ & 0.38 & 0.04 & $\begin{array}{l}\text { Flavocytochrome c sulphide dehydrogenase, flavin-binding: Enzymes found in S- } \\
\text { oxidizing bacteria such as the purple phototrophic bacteria Chromatium vinosum (Finn et al., } \\
\text { 2008). }\end{array}$ \\
\hline $\begin{array}{l}\text { PF04879 } \\
151 / 161\end{array}$ & 0.37 & 0.05 & $\begin{array}{l}\text { Molybdopterin oxidoreductase Fe4S4 domain: Is found in a number of } \\
\text { reductase/dehydrogenase families, which include the periplasmic nitrate reductase precursor } \\
\text { and the formate dehydrogenase alpha chain, i.e., Wolinella succinogenes polysulfide } \\
\text { reductase chain. Salmonella typhimurium thiosulfate reductase (gene phsA). }\end{array}$ \\
\hline $\begin{array}{l}\text { PF08770 } \\
45 / 161\end{array}$ & 0.35 & 0.03 & $\begin{array}{l}\text { Sulphur oxidation protein SoxZ: SoxZ sulfur compound chelating protein, part of the } \\
\text { complex known as the Sox enzyme system (for sulfur oxidation) that is able to oxidize } \\
\text { thiosulfate to sulfate with no intermediates in Paracoccus parantropus (Caspi et al., 2012). }\end{array}$ \\
\hline
\end{tabular}

Identification of S-based genomes using the Sulfur Score

To test whether Pfam entropies can be combined to capture the S-related metabolism, we The obtained SS and the corresponding taxonomy according in NCBI for each genome can be found in Table S6. Then we classified all the genomes according to their metabolic capabilities related microorganisms not included in Suli with $S S>4$ (in total 192), which were curated

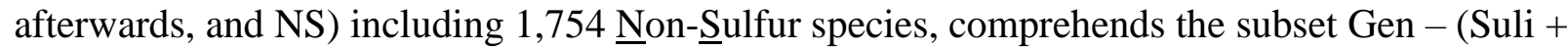


369

370

371

372

373

374

375

376

377

378

379

380

381

382

383

384

385

386

387

388

389

390

391

392

393

394

395

396

397

398

to rule out all false positives. However, $S S=5.231$ is sufficient to achieve a FPR $<0.05$. Figure $5 \mathrm{C}$ breaks down the species in Suli according to the metabolic guilds of the microbial mat model observing the clear difference between the distribution of SS in NS and Sulfur-related genomes (Suli and Sur). Finally, the $S S$ values of candidate genomes in Sur are also plotted to show that they are comparable to the metabolic guilds of the S-cycle. Figure 5D shows the result of manually assigning candidate genomes in Sur to classes in terms of their ecological capabilities (see Table S7).

Out of 192 Sur genomes, 68 are known to metabolize S-compounds under culture conditions in literature reports. For instance, Sideroxydans lithotrophicus ES-1, a microaerophilic Fe-oxidizing bacterium has been observed to grow using thiosulfate as an energy source (Emerson et al., 2013). Another 59 Sur organisms were isolated from Sulfur-rich environments such as hot springs or solfataric muds, including uncultured species with genomes assembled from metagenomic sequences. For instance, Candidatus Desulforudis audaxviator MP104C was isolated from basalt-hosted fluids of the deep subseafloor (Jungbluth et al., 2016). Moreover, an unnamed endosymbiont of a scaly snail was sampled from a black smoker chimney (Nakagawa et al., 2014). Finally, the archaon Geoglobus ahangari was isolated from a 2,000m depth hydrothermal vent (Manzella et al., 2015).

Combining these two subsets, $68 \%$ of species in Sur were confirmed by curation to be Sbased.

We additionally confirmed the importance of S-cycle in gastrointestinal microbes of the genus Campylobacter by detecting 20 genomes with high SS values. This result is consistent with the implication of S-metabolism in the low oxygen environment of the host guts, where several inorganic (e.g., sulfates, sulfites) or organic (e.g., dietary amino acids and host mucins) S-compounds originate and are metabolized by several microorganisms. Among the microbes involved in colonic S-metabolism are SRB, many methanogens and Campylobacter genus (Carbonero et al., 2012). Furthermore, some species of Campylobacter have been isolated from deep sea hydrothermal vents (Nakagawa et al., 2007), suggesting that this genus plays an important role in the S cycle. The remaining species in Sur were classified in these categories: biorremediation (7), Fe-environment (2), marine (2), peatlands (2) and other environments (32). 

score to accurately predict, classify and measure the importance of the S-cycle in both in culture-derived and novel sequenced genomes without prior culture and biochemical knowledge.

\section{Detecting key sulfur metagenomic environments with the Sulfur Score}

405 Encouraged by the genomic benchmark results described above, we set out to evaluate the 406 importance of the S-cycle across 935 metagenomes in dataset Met. We calculated the SS for each metagenome taking into account its Mean Size Length (MSL) and the corresponding entropies calculated in dataset GenF (Table S8). The global distribution of Met is mapped in Figure 6A, with $S S$ scores colored from yellow to red. To discriminate the most important S-related environments, those with $S S$ values equal or larger than the $95^{\text {th }}$ percentile of the corresponding MSL category are shown with blue borders.

In order to analyze some ecological patterns of the metagenomes they were further sorted

414 implemented in MG-RAST. Each feature corresponds to one of 13 environmental packages (EP)

415 that standardize metadata describing particular habitats that are applicable across all GSC

416 checklists and beyond (Field et al., 2014). The EPs represent a broad and general classification

417 containing particular features. For example, the "water" EP includes 330 metagenomes from our

418 dataset belonging to several features such as freshwater, lakes, estuarine, marine, hydrothermal

419 vents, etc. Each of these features has different ecological capabilities in terms of biogeochemical 420 cycles; therefore, will likely yield different $S S$ values. The results are shown in Figure 6B. In

421 general, all the metagenomes derived from hydrothermal vents (2), marine benthic (6), intertidal

422 (8), and our CCC microbial mats had $S S$ values above the $95^{\text {th }}$ percentile, highlighting the

423 importance of the S-cycle in these environments. In contrast, the metagenomes belonging to

424 features such as sub-terrestrial habitat (7), saline evaporation pond (24) or organisms associated

425 habitat (7) displayed consistently low or even negative $S S$ values, indicating an insignificant

426 presence of S-metabolic pathways in those environments. The remaining features have

427 intermediate median $S S$ values and contain occasionally individual metagenomes with $S S$ values

428 above the $95^{\text {th }}$ percentile, such as freshwater, marine, ocean or biofilm environments. 
Using our approach, we identified and annotated a total of 50 high-scoring metagenomes (Table S9). According to their corresponding literature and associated metadata, all these environments can be described as Sulfur-related as they are reported to be involved in mineralization, uptake, and recycling processes of S-compounds, for example:

i) Metagenome 4525341.3 (MSL=172aa, $S S=9.287$ ) sequenced from costal Oligochaete worm Olavius algarvensis, from which metabolic pathway reconstruction revealed the presence of gamma proteobacteria symbionts that are S-oxidizing and SRB. The chemoautotrophic symbionts provide their hosts with multiple sources of nutrition such as organic carbon from autotrophic $\mathrm{CO}_{2}$ fixation driven by oxidation of reduced inorganic S-compounds (Woyke et al., 2006).

ii) Metagenome $4441663.3(\mathrm{MSL}=158 \mathrm{aa}, S S=9.986)$ sampled from an hydrothermal vent in the Mariana Trough in 2003 (depth: 2,850 m, fluid temperature:106 ${ }^{\circ} \mathrm{C}$ ) (Nakai et al., 2011). The hydrothermal vents are highly productive ecosystems fueled by a number of reduced inorganic substances (e.g., reduced S-compounds, hydrogen or methane) contained in the deep hydrothermal fluids. Through the oxidation of such compounds, chemolithoautotrophic microorganisms gain energy, which can be used for the fixation of inorganic carbon, mediating the transfer of energy from the geothermal source to higher trophic levels and thus form the basis of the unique food chains existing in these environments (Hügler et al., 2010) .

iii) Metagenomes 4510162.3, 4510168.3 and 4510170.3, with MSL=32, and SS 7.676, 7.781 and 7.772, respectively, were sampled from the marine deep-sea surface sediments around the Deep-water horizon spill in the Gulf of Mexico. They belong to ocean feature of EP sediment. The activity of key hydrocarbon degradation pathways was confirmed in these metagenomic deepsea sediments and the presence of metabolic pathways involved in $\mathrm{C}, \mathrm{N}$ and $\mathrm{S}$ cycles were also confirmed in the metagenomic analysis described in (Mason et al., 2014).

iv) Microbial mats from CCC were also detected above the 95th percentile (MSL: 100 and $S S:$ 8.945, 9.093, 9.0, and 8.978). Samples were obtained from an ultra-oligotrophic shallow lake recovered from a desiccation event due to water over-exploitation. The sequenced microbial mats showed a clear layered visual pattern structure following the S-metabolic guilds described in Figure 2A. These were assigned to EP and feature "microbial_mat_ccc".

v) Metagenomes 4516637.3 and 4516803.3 (MSL=30, SS=7.762 and 7.753 respectively), belong to EP and feature "air". Their high SS are consistent with the biogeochemical S-cycle, since the importance of gas-phase reactions of S-compounds and the formation and subsequent 
460

461

462

463

464

465

466

467

468

469

470

471

472

473

474

475

476

477

478

479

480

481

482

483

484

485

486

487

488

489

involvement of sulfate aerosols as cloud-forming nuclei is well established. While these reactions can be carried out without microbial intervention, it has been suggested that microbial communities might contribute to the degradation of some of these S-compounds (Cao et al., 2014).

To test the reproducibility and robustness of the Sulfur Score, we conducted two further analyses. In the first one, summarized in Figure S6, we compared SS estimates of the Met dataset which combined Pfam entropies computed in 2014 and 2017. Despite the changes of both, the Pfam database and the Suli list, overall we find a strong correlation, yielding an $R^{2}=0.912$ (Figure S6 A). A kernel density analysis of the comparison suggests a different behavior of low and high $S S$ scores, with the latter being more reproducible (see Figure S6B). In the second analysis, we quantitatively tested to what extent the entropy estimates of the set of 112 Pfam domains affect the outcome of the $S S$ in Gen and Met. To do so, we subsampled randomly $\approx 50 \%$ of those domains to compute the SS 1,000 times for each of the 2,017 nr-genomes and 935 metagenomes. The results, summarized in Table S10, confirm that $S S$ values computed with random subsets of Pfam domains are generally lower than $S S$ derived from the full list $(\mathrm{n}=112)$ of S-related Pfam domains in Sucy, regardless of MSL. However, as shown in Figure S7 for MSL=60, the overall ranking of metagenomes produced by computing $S S$ values only with a subset of Pfam domains is broadly equivalent. Altogether, these analyses suggest that the choice of protein domains does affect the absolute scores obtained. However, high scoring metagenomes are ranked highly, even when only a reduced set of Pfam domains are employed.

The latter result confirms that a comprehensive database of protein-coding genes derived from a systematic reconstruction of global biogeochemical cycles, is necessary to apply the algorithm to quantify the importance of any given elements biogeochemical cycle in a given environment.

\section{CONCLUSIONS}

In this study, we proposed a computational approach to address the complexity of global biogeochemical cycles on a multi-genomic scale. This methodology requires the curation of an inventory of biotic players (including genes, molecular pathways and microorganisms) and abiotic compounds involved in the cycle of interest. We focused on the S-cycle due to is 
490

importance on the biogeochemistry of the planet, but in principle this approach could be applied to any other cycle with microbial participation.

For the first time, we systematically build two databases that describe the complexity of the S-cycle based on the minimum ecosystem concept and the microbial mat model. We compiled available non-redundant fully sequenced S-based microorganisms (Suli), and all the known metabolic pathways involved in the S-cycle, taking into account also relevant abiotic Scompounds (Sucy). We used these databases as the input of a computational entropy-based approach that works in two stages. First, we used the individual entropies of protein domains annotated in Sucy to propose a list of 12 molecular markers of the S-cycle and then combined these in order to produce the Sulfur Score, a measure that informs about the presence of the molecular machinery involved in $\mathrm{S}$ metabolism. We benchmarked the predictive value of the Sulfur Score by producing a ROC curve, and tested its robustness with simulations against randomly subsampled subsets of the curated protein domains.

Altogether, we propose that this method can be used to evaluate other global biogeochemical cycles or complex molecular pathways across genomic and metagenomic sequence datasets, therefore allowing the detection of environmental patterns and informative samples using a single score.

\section{Acknowledgements.}

Valerie De Anda is a doctoral student from Programa de Doctorado en Ciencias Biomédicas, Universidad Nacional Autónoma de México (UNAM) and received fellowship 356832 from CONACYT. We also acknowledge funding from WWF-Alianza Carlos Slim, as well as SepCiencia Básica Conacyt Proyect 238245 both to VS and LEE.

\section{Conflicts of interest}

The authors declare no conflict of interest

\section{Figure Legends}

Figure 1. Computational pipeline for the analysis of the different levels of complexity of the sulfur cycle (S-cycle). The first step is to obtain the datasets. The biogeochemical processes of 
520

521

522

523

524

525

526

527

528

529

530

531

532

533

534

535

536

537

538

539

540

541

542

543

544

545

546

547

548

the S-cycle were compiled in two lists. First, the most important S-compounds involved in abiotic or abiotic reactions were curated to produce a database of metabolic pathways, redox reactions, enzymatic numbers and their corresponding coding genes (Sucy). Second, a list of Sbased microorganisms (Suli) was also curated and compiled using the information of the Microbial Mat Model described in Figure 2. Then a total of 1,000 list of random genomes were used as negative control (Rlist). The information gathered was then used to evaluate the 'omic' datasets (Gen, GenF, Met). Stages 2 to 4 summarize the determination of the Sulfur Score (SS) with sets of peptide sequences of increasing mean size length (MSL, in this example A, B and C). $S S$ is calculated by summation of the entropy of 112 scanned protein domains, each one with a certain entropy value $\left(H^{\prime}\right)$.

Figure 2. Sulfur cycle in small and planetary scale. A) Microbial Mat Model: Simplified scheme of the relevant reactions carried out in microbial mats according to the redox potential. The redox couples (at $\mathrm{pH}$ 7) are approximate; the exact values depend upon how the reactions are coupled. 1) oxygenic photosynthesis by Cyanobacteria 2) chemosynthesis by chemolithotrophic color-less sulfur bacteria (CLSB), anoxygenic photosynthesis by 3) purple sulfur bacteria (PSB) and 4) green sulfur bacteria (GSB). sulfate reduction performed by 5) sulfate reducing $\underline{b}$ acteria (SRB). B) Sulfur cycle at planetary scale. Most important organic and inorganic S-compounds derived from biogeochemical processes arranged according to the Standard Gibbs free energy of formation described in Caspi et al., (2012). The left column indicates whether specific microorganisms are able to use those S-compounds, as a source of Carbon (C), Nitrogen (N), Energy (E) or Electron donors $\left({ }^{\circ}\right)$. Double asterisks indicate if the Scompound is used as sole source, of $\mathrm{C}, \mathrm{N}$, or E. The corresponding electron acceptors in redoxcoupled reactions using the S-compound as electron donor are not show. The right column indicates whether the S-compounds are used as fermentative substrate $(\mathrm{F})$ or terminal electron acceptor in respiratory processes $(\mathrm{R})$. Colored boxes summarized the metabolic guilds involved in the metabolism of S-compounds, in oxidation (i.e., CLSB, SOM, PSB, and GSB) or reduction $(\mathrm{SR}, \mathrm{SRB})$ process. Some redox coupling reactions carried out by the latter metabolic guilds are showed in panel A. The complete list of S-based microorganisms (Suli) is found in Table S1. Figure based on annotations from MetaCyc (Caspi et al., 2012). 
Figure 3. Comprehensive representation of the global biogeochemical S-cycle assembled from many metabolic pathways found in a variety of organisms combined in a single cell. To the best of our knowledge, all the molecular pathways involved in the metabolism of sulfur compounds, described in Figure 2B, are included. The enzymatic steps are depicted as rectangles followed by arrows indicating the direction of the reaction. Green hexagons represent metabolic links to other metabolisms. Bold dashed arrows indicate bidirectional reactions. Inorganic S-compounds have been arranged according to their reduction potential, from the most oxidized (yellow) to the most reduced (red) compounds. Grey rectangles indicate enzymes acting in disproportionation processes in which a reactant is both oxidized and reduced in the same chemical reaction, forming two separate compounds. Input biogeochemical S-compounds are shown outside and connected with bold arrows. Dashed arrows indicate Scompounds excreted out of the cell. The upper half of the modelled cell depicts the processes involved in the use of organic S-compounds (orange circles) found in natural environments and used as source of carbon, sulfur and/or energy in several aerobic/anaerobic strains described in Figure 2.

Figure 4. Clustering of the Pfam relative entropies obtained in Gen and GenF produced with the Ward method. Log frequency of the entropy values computed in the random test is colored in purple (see scale bar). Cluster 0 (blue) groups protein domains with low relative entropy that overlap with the random distribution. Cluster 1 (green) includes the Pfam domains that fulfill the requirements to be used as molecular markers (high H' and low standard deviation, std). Red dots (cluster 2) correspond to Pfam domains with high H' and std.

Figure 5. Distribution of Sulfur Score $(S S)$ in genomes of dataset Gen. A) Subsets of nonredundant genomes: i) genomes annotated in Suli $(n=161)$; ii) Sur, genomes not listed in Suli with $S S>4$ and candidates to be S-related microorganisms $(\mathrm{n}=192)$; iii) rest of the genomes in Gen (NS, n=1,754). According to the curated species, True Positives can be defined as genomes with $\mathrm{SS}>\max \left(\mathrm{SS}_{\mathrm{NS}}\right)$ distribution, whereas True Negatives are those with $\mathrm{SS}<$ $\min \left(\mathrm{SS}_{\text {Suli }}\right)$. B) ROC curve with Area Under the Curve (AUC) indicated together with thresholds for some False Positive Rates (FPR). C) Distribution of SS for different S-metabolic 
578 guilds according to the microbial mat model (Figure 2A) and also the genomes in Sur. D)

579 Assignment of the 192 genomes in Sur to ecological categories based on literature reports.

580

581

582

583

584

585

586

587

588

589

590

591

592

593

594

595

596

597

598

599

600

601

602

603

604

605

606

Figure 6. Distribution of Sulfur Score (SS) in the metagenomic dataset Met. A) Geo-localized metagenomes sampled around the globe are colored according to their $S S$ values. The following cut-off values correspond to the $95^{\text {th }}$ percentiles of seven Mean Size Length classes (30, 60, 100, 150, 200, 250 and 300 aa): 7.66, 9.70, 8.81, 8.51, 8.18, 8.98 and 7.61, respectively. Circles with thick blue border indicate metagenomes with $\mathrm{SS} \geq$ the $95^{\text {th }}$ percentile. B) Distribution of SS values observed in 935 metagenomes classified in terms of features (X-axis) and colored according to their environmental packages. Features are sorted according to their median $S S$ values. ccc: metagenomes from Cuatro Cienegas, Coahuila, Mexico. Green lines indicate the lowest and largest $95^{\text {th }}$ percentiles observed across MSL classes.

\section{References}

Alcaraz, L.D., Olmedo, G., Bonilla, G., Cerritos, R., Hernández, G., Cruz, A., et al. (2008) The genome of Bacillus coahuilensis reveals adaptations essential for survival in the relic of an ancient marine environment. Proc. Natl. Acad. Sci. U. S. A. 105: 5803-8.

Bolhuis, H., Cretoiu, M.S., and Stal, L.J. (2014) Molecular Ecology of Microbial Mats. FEMS Microbiol. Ecol. 3: 1-16.

Canfiel. DE, Thamdrup B, Kristensen E. (2005) Aquatic Geomicrobiology, Volume 48 (Advances in Marine Biology). Elsevier Academic Press.

Cao, C., Jiang, W., Wang, B., Fang, J., Lang, J., Tian, G., et al. (2014) Inhalable Microorganisms in Beijing' s PM 2.5 and PM 10 Pollutants during a Severe Smog Event. Enviromental Sci. Technol. 48: 1499-1507.

Carbonero, F., Benefiel, A.C., Alizadeh-Ghamsari, A.H., and Gaskins, H.R. (2012) Microbial pathways in colonic sulfur metabolism and links with health and disease. Front. Physiol. 3: $1-11$.

Caspi, R., Altman, T., Dreher, K., Fulcher, C. a, Subhraveti, P., Keseler, I.M., et al. (2012) The 
607

608

609

610

611

612

613

614

615

616

617

618

619

620

621

622

623

624

625

626

627

628

629

630

631

632

633
MetaCyc database of metabolic pathways and enzymes and the BioCyc collection of pathway/genome databases. Nucleic Acids Res. 40: D742-53.

Chen, L., Hu, M., Huang, L., Hua, Z., Kuang, J., Li, S., and Shu, W. (2015) Comparative metagenomic and metatranscriptomic analyses of microbial communities in acid mine drainage. ISME J. 9(7): 1579-1592.

Commenges, D. (2015) Information Theory and Statistics: an overview. ARXIV preprint arXiv: 1511.00860.

Dahl (2017) Modern Topics in the Phototrophic Prokaryiotes. Metabolism, Bioenergetics and Omics. Springer International Publishing pp 27-66, 10.1007/978-3-319-51365-2_2.

Emerson, D., Field, E.K., Chertkov, O., Davenport, K.W., Goodwin, L., Munk, C., et al. (2013) Comparative genomics of freshwater Fe-oxidizing bacteria: implications for physiology, ecology, and systematics. Front. Microbiol. 4: 254.

Falkowski, P.G., Fenchel, T., and Delong, E.F. (2008) The microbial engines that drive Earth's biogeochemical cycles. Science 320: 1034-9.

Field, D., Sterk, P., Kottmann, R., Smet, J.W. De, Amaral-zettler, L., Cole, J.R., et al. (2014) Genomic Standards Consortium Projects The Genomic Standards Consortium Initiating and Maintaining a Project within the GSC The GSC Project Description template provides a References : Stand. Genomic Sci. 599-601.

Finn, R.D., Clements, J., and Eddy, S.R. (2011) HMMER web server: interactive sequence similarity searching. Nucleic Acids Res. 39: W29-37.

Finn, R.D., Tate, J., Mistry, J., Coggill, P.C., Sammut, S.J., Hotz, H.-R., et al. (2008) The Pfam protein families database. Nucleic Acids Res. 36: D281-8.

Halevy, I., Peters, S.E., and Fischer, W.W. (2012) Sulfate burial constraints on the Phanerozoic sulfur cycle. Science 337: 331-4.

Hedges, J.I. (1992) Global biogeochemical cycles: progress and problems. Mar. Chem. 39: 6793.

Herman EK and Kump LR (2005) Biogeochemistry of microbial mats under Precambrian 
environmental conditions : a modelling study. Geob 3: 77-92.

635 Hertz, G.Z. and Stormo, G.D. (1999) Identifying DNA and protein patterns with statistically 636 significant alignments of multiple sequences. Bioinformatics 15: 563-77.

Hügler, M., Gärtner, A., and Imhoff, J.F. (2010) Functional genes as markers for sulfur cycling and $\mathrm{CO} 2$ fixation in microbial communities of hydrothermal vents of the Logatchev field. FEMS Microbiol. Ecol. 73: 526-537.

Jones, P., Binns, D., Chang, H.Y., Fraser, M., Li, W., McAnulla, C., et al. (2014) InterProScan 5: Genome-scale protein function classification. Bioinformatics 30: 1236-1240.

Jungbluth SP, Glavina del Rio T, Tringe SG, Stepanauskas R, Rappé MS. (2016) Genomic comparisons of a bacterial lineage that inhabits both marine and terrestrial deep subsurface systems. PeerJ Preprints 4:e2592v1https://doi.org/10.7287/peerj.preprints.2592v1

Kanehisa, M. and Goto, S. (2000) KEGG: kyoto encyclopedia of genes and genomes. Nucleic Acids Res. 28: 27-30.

Khodadad, C.L.M. and Foster, J.S. (2012) Metagenomic and metabolic profiling of nonlithifying and lithifying stromatolitic mats of Highborne Cay, The Bahamas. PLoS One 7: e38229.

Kullback, S. and Leibler, R.A. (1951) On Information and Sufficiency. Ann. Math. Stat. 22: 79-86.

Li, Y., Yu, S., Strong, J., and Wang, H. (2012) Are the biogeochemical cycles of carbon, nitrogen, sulfur, and phosphorus driven by the "FeIII-FeII redox wheel" in dynamic redox environments? J. Soils Sediments 12: 683-693.

Llorens-Marès, T., Yooseph, S., Goll, J., Hoffman, J., Vila-Costa, M., Borrego, C.M., et al. (2015) Connecting biodiversity and potential functional role in modern euxinic environments by microbial metagenomics. ISME J. 9(7): 1579-92.

Loy, A., Ku, K., Lehner, A., Drake, H.L., and Wagner, M. (2004) Microarray and Functional Gene Analyses of Sulfate-Reducing Prokaryotes in Low-Sulfate , Acidic Fens Reveal Cooccurrence of Recognized Genera and Novel Lineages. Appl. Environ. Microbiol. 70: 
Magrane, M. and Consortium, U.P. (2011) UniProt Knowledgebase: A hub of integrated protein data. Database 2011: 1-13.

664

665

666

667

668

669

670

671

672

673

674

675

676

677

678

679

680

681

682

683

684

685

686

687
Manzella, M.P., Holmes, D.E., Rocheleau, J.M., Chung, A., Reguera, G., and Kashefi, K. (2015) The complete genome sequence and emendation of the hyperthermophilic, obligate iron-reducing archaeon “Geoglobus ahangari” strain 234T. Stand. Genomic Sci. 10: 77.

Mason, O.U., Scott, N.M., Gonzalez, A., Robbins-Pianka, A., Bælum, J., Kimbrel, J., et al. (2014) Metagenomics reveals sediment microbial community response to Deepwater Horizon oil spill. ISME J. 8: 1464-75.

Meyer, B. and Kuever, J. (2007) Molecular analysis of the diversity of sulfate-reducing and sulfur-oxidizing prokaryotes in the environment, using aprA as functional marker gene. Appl. Environ. Microbiol. 73: 7664-79.

Morales, S.E. and Holben, W.E. (2011) Linking bacterial identities and ecosystem processes: Can "omic" analyses be more than the sum of their parts? FEMS Microbiol. Ecol. 75: 216.

Moreno-Hagelsieb, G., Wang, Z., Walsh, S., and ElSherbiny, A. (2013) Phylogenomic clustering for selecting non-redundant genomes for comparative genomics. Bioinformatics 29: 947-9.

Nakagawa, S., Shimamura, S., Takaki, Y., Suzuki, Y., Murakami, S., Watanabe, T., et al. (2014) Allying with armored snails: the complete genome of gammaproteobacterial endosymbiont. ISME J. 8: 40-51.

Nakagawa, S., Takaki, Y., Shimamura, S., Reysenbach, A.-L., Takai, K., and Horikoshi, K. (2007) Deep-sea vent epsilon-proteobacterial genomes provide insights into emergence of pathogens. Proc. Natl. Acad. Sci. U. S. A. 104: 12146-12150.

Nakai, R., Abe, T., Takeyama, H., and Naganuma, T. (2011) Metagenomic Analysis of 0.2- $\mu$ Passable Microorganisms in Deep-Sea Hydrothermal Fluid. Mar. Biotechnol. 13: 900 908. 
688

Newman, D.K. and Banfield, J.F. (2002) Geomicrobiology: how molecular-scale interactions underpin biogeochemical systems. Science 296: 1071-7.

Odum EP (1993) Ecology and our endangered life-support systems, 2nd edn. Sinauer Associates Inc., Sunderland, Massachusetts. 301 pp.

Olson, K.R., Straub, K.D., and Straub, K.D. (2016) The Role of Hydrogen Sulfide in Evolution and the Evolution of Hydrogen Sulfide in Metabolism and Signaling The Role of Hydrogen Sulfide in Evolution and the Evolution of Hydrogen Sulfide in Metabolism and Signaling. Physiology 31: 60-72.

Pedroni, P., Volpe, A.D., Galli, G., Mura, G.M., Pratesi, C., and Grandi, G. (1995) Characterization of the locus encoding the [Ni-Fe] sulfhydrogenase from the archaeon Pyrococcus furiosus: Evidence for a relationship to bacterial sulfite reductases. Microbiology 141: 449-458.

Pinckney, J.L. and Paerl, H.W. (1997) Anoxygenic photosynthesis and nitrogen fixation by a microbial mat community in a bahamian hypersaline lagoon. Appl. Environ. Microbiol. 63: $420-6$.

Quaiser, A., Zivanovic, Y., Moreira, D., and López-García, P. (2011) Comparative metagenomics of bathypelagic plankton and bottom sediment from the Sea of Marmara. ISME J. 5: 285-304.

Rabus, R., Hansen, T., and Widdel, F. (2013) "Dissimilatory sulfate- and sulfur-reducing prokaryotes," in The Prokaryotes, eds E. Rosenberg, E. Delong, S. Lory, E. Stackebrandt, and F. Thompson. Heidelberg: Springer. 309-404.

Santos, A.A., Venceslau, S.S., Grein, F., Leavitt, W.D., Dahl, C., Johnston, D.T., and Pereira, I.A.C. (2015) A protein trisulfide couples dissimilatory sulfate reduction to energy conservation. Science (80-. ). 350: 1541-1545.

Stewart, F.J., Dmytrenko, O., Delong, E.F., and Cavanaugh, C.M. (2011) Metatranscriptomic analysis of sulfur oxidation genes in the endosymbiont of solemya velum. Front. Microbiol. 2: 134. 
716 Swingley, W.D., Meyer-Dombard, D.R., Shock, E.L., Alsop, E.B., Falenski, H.D., Havig, J.R., 717 and Raymond, J. (2012) Coordinating environmental genomics and geochemistry reveals metabolic transitions in a hot spring ecosystem. PLoS One 7: e38108.

719 Taguchi, Y., Sugishima, M., and Fukuyama, K. (2004) Crystal Structure of a Novel ZincBinding ATP Sulfurylase from Thermus. Biochemistry 43: 4111-4118.

721 Tu, Q., Yu, H., He, Z., Deng, Y., Wu, L., Van Nostrand, J.D., et al. (2014) GeoChip 4: A 722 functional gene-array-based high-throughput environmental technology for microbial community analysis. Mol. Ecol. Resour. 14: 914-928.

Widder, S., Allen, R.J., Pfeiffer, T., Curtis, T.P., Wiuf, C., Sloan, W.T., et al. (2016) function and dynamics. ISME J. 10: 2557-2568.

Woyke, T., Teeling, H., Ivanova, N.N., Huntemann, M., Richter, M., Gloeckner, F.O., et al. (2006) Symbiosis insights through metagenomic analysis of a microbial consortium. Nature 443: 950-5. cropping. ISME J. 8(10): 2045-55. 
Random

Observed P(i)

Negative control random list

Step 1
Curated

Observed P(i)
Genomic Dataset

Expected Q(i)

Systematic reconstruction of the biogeochemical S-cycle

$$
\text { мMм }
$$

Taxonomic Representatives

Molecular reconstruction

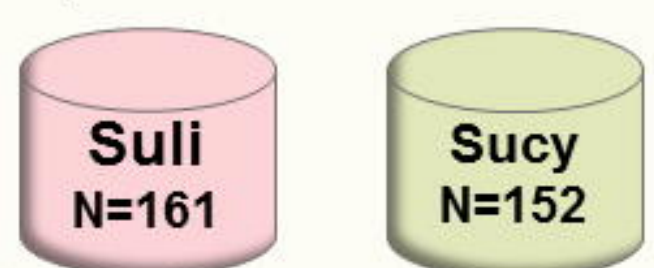

2,107 non-reduntant complete sequenced prokaryotic genomes

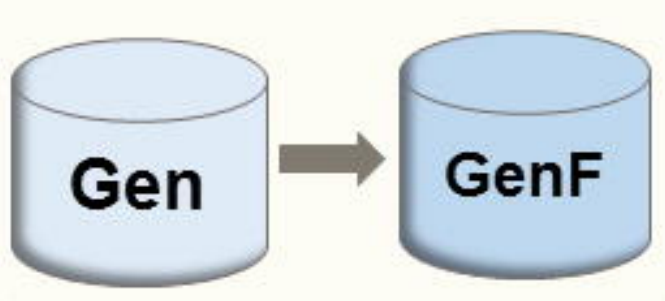

Metagenomic

Dataset

935 metagenomes from MG-RAST

Met

Step 3

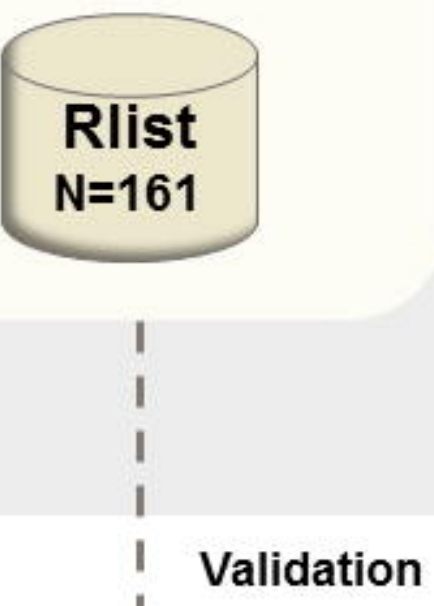

bioRxiv preprint doi: https://doi.org/10.1101/148775; this version posted June 11, 2017. The copyright holder for this preprint (which was not

Step 2
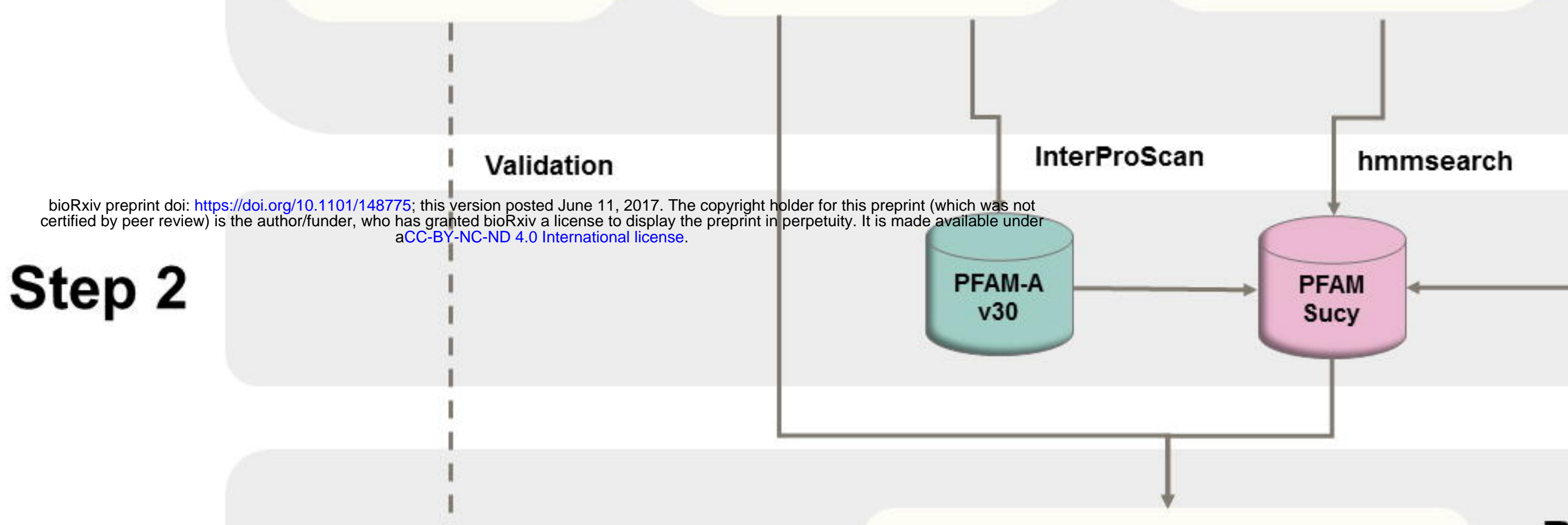

$$
\mathbf{H}^{\prime}=\sum_{i} P(i) \log _{2} \frac{P(i)}{Q(i)}
$$

Relative Entropy

$$
S S=\sum_{i=1}^{112} \mathrm{H}^{\prime}
$$

\section{Sulfur Score sS}

Step 4

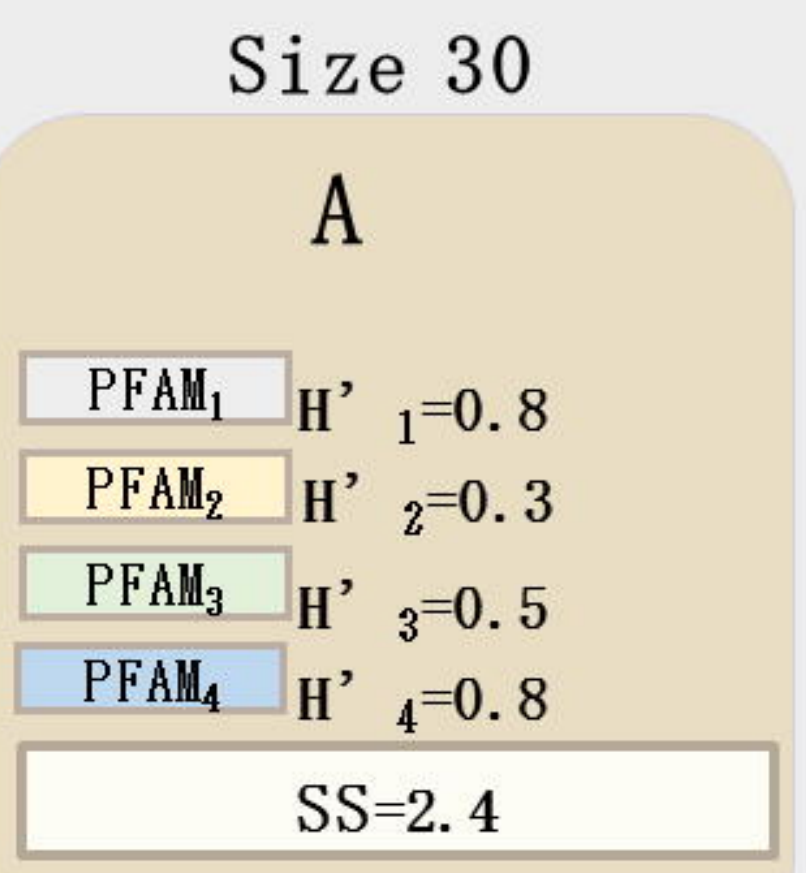

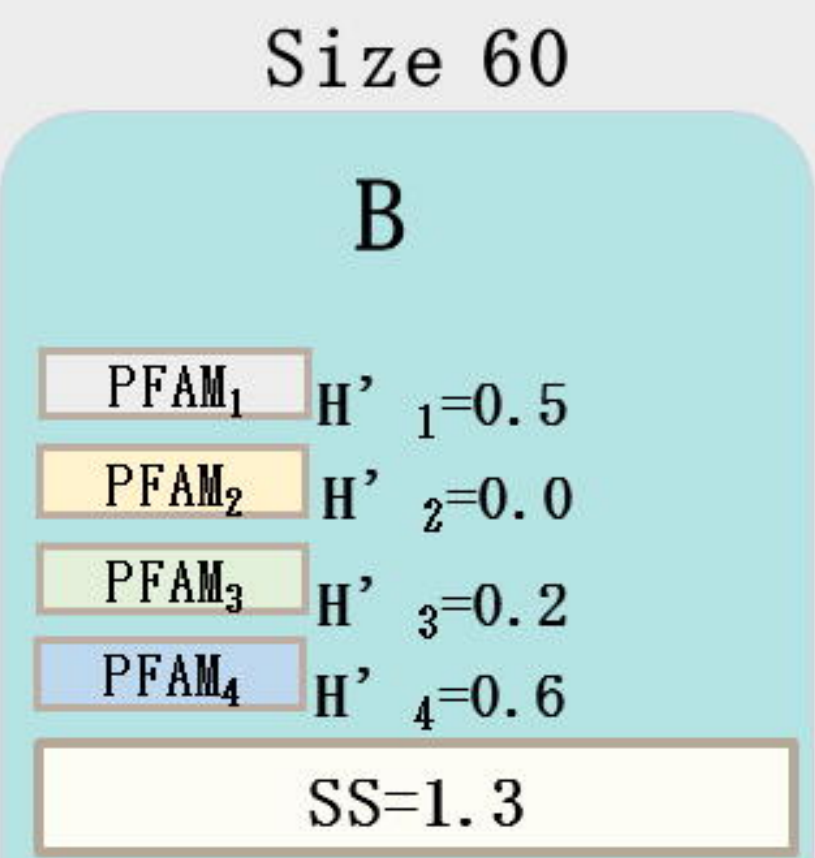

\begin{tabular}{|c|c|}
\hline $\mathrm{PFAM}_{1}$ & $H^{\prime}{ }_{1}=0.9$ \\
\hline $\mathrm{PFAM}_{2}$ & $\mathrm{H}^{\prime}{ }_{2}=0.6$ \\
\hline $\mathrm{PFAM}_{3}$ & $H^{\prime}{ }_{3}=0.5$ \\
\hline $\mathrm{PFAM}_{4}$ & $H^{\prime}{ }_{4}=1.3$ \\
\hline & $\mathrm{SS}=3.3$ \\
\hline
\end{tabular}

Size 150

C 


\section{S-cycle in microbial mats}
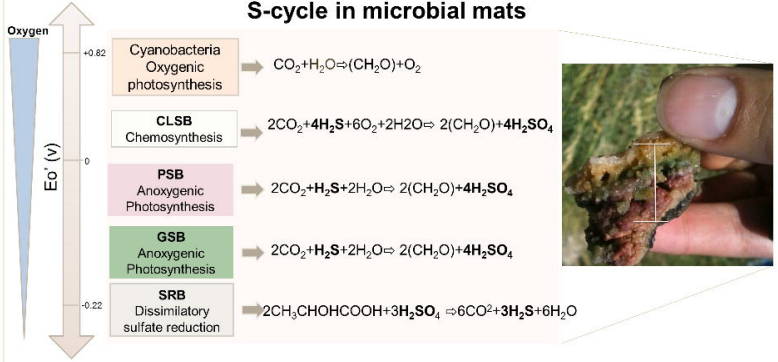

\section{S-cycle at global scale}

B S-compound used as source of Carbon (C). Nitrogen (N), Energy (E). Electron donor ${ }^{\circ}$, unique source ${ }^{* *}$

Thermithiobacillus tepidarius, Acidithiobacillus ferrooxidans, Acidithiobacillus thiooxidans $(E)^{x^{*}}$ Thioalkalivibrio thiocyanoxidans, Thiobacilius aquaesulis (E) ${ }^{\text {** }}$

Ruegeria pomeroyi DSS-3 (CE), Roseovarius nubinhibens ISM (CE), Chromohalobacter salexigens DSM 3043 (CE)**

Ratstonia eutropha $\mathrm{H} 16$ (CE)
Acidianus
ambivalens
Allochromatium vinosum and Thiocapsa
roscoporsicina
Thiobacillus thioparus Thiobacillus denitrificans.
Beggiatoa

Paracoccus pantotrophus (E)**

$\begin{array}{llll}\text { CLSB }^{\circ} \text { SOM } & \text { GSB }^{\circ} \text { PSB }^{\circ}\end{array}$

\section{Methyiosulfonomonas,} Marinosulfonomonas, and some strains of Hyphomicrobium and Methylobacterium (CE)

Pseudomonas aeruginosa TAU-5 (CE) Castolianiella dofograns NKNTAU (E**) Paracoccus denitrificans NKNIS ( $\mathrm{E}^{\star *}$ Paracoccus pantotrophus NKNCYSA (E)

Arthrobacter methylotrophus (CE) Anthrobacter sulfonivorans (CE) ${ }^{* *}$ Hyphomicrobium sulfonivorans (CE)*v

\section{Raistonia eutropha $\mathrm{H} 16$ (N)**
Ruegeria pomeroyi DSS-3
(CE) \\ Thiobacillus thioparus TK-m (E) Paracoccus denitrificans (E)}

\begin{tabular}{ll|l|l} 
CLSB $^{\circ}$ SOM $^{\circ}$ GSB $^{\circ}$ & PSB
\end{tabular}

CLSB $^{\circ}$ GSB $^{\circ} \quad$ PSB $^{\circ}$

Sulfitobacter sp. EE-36, Marinomonas sp MED121, Marinomonas sp. MWYL1, Ruegeria pomeroyi DSS-3, Roseovarius nubinhibens ISM: (CE)

Thiobacillus thioparius, TK-m, Thiobacillus thioparius, T5 and Hyphomicrabium sp (CE)
$\Delta_{\mathrm{f}} \mathrm{G}^{\circ}$

of each S-compound (kcal/mol)

\begin{tabular}{|c|c|}
\hline$\underset{\text { Tetrathiona }}{\mathbf{S}_{4} \mathbf{O}_{6}{ }^{2-}}$ & $e^{-245.5}$ \\
\hline $\begin{array}{l}\mathrm{SO}_{4}{ }^{2-} \\
\text { Sulfate }\end{array}$ & -179.2 \\
\hline
\end{tabular}

$\mathrm{C}_{3} \mathrm{H}_{4} \mathrm{O}_{6} \mathrm{~S}$ Sulfolactate

$\mathrm{C}_{2} \mathrm{H}_{2} \mathrm{O}_{5} \mathrm{~S}$

${ }_{\text {Sulfoacetate }}^{\mathrm{C}_{2} \mathrm{H}_{2} \mathrm{O}_{5} \mathbf{S}}-1000$

$\mathrm{SO}_{3}{ }^{2-}$

Sulfite -127.4

$\mathrm{C}_{3} \mathrm{H}_{6} \mathrm{NO}_{5} \mathrm{~S}$

L-cysteate

$\mathrm{S}_{2} \mathrm{O}_{3}{ }^{2}$

Thiosulfate $^{-112.7}$

$\mathrm{CH}_{3} \mathrm{O}_{3} \mathrm{~S}$

$\begin{array}{ll}\text { Mothane } & -71.5 \\ \text { sulionate } & \end{array}$

Desulfonispora thiosulfatigenes

$\begin{array}{ll}\mathrm{C}_{2} \mathrm{H}_{7} \mathrm{NO}_{3} \mathrm{~S}_{49.9-} & \text { GKNTAU (F) } \\ \text { Taunine } & \text { Bilophila wad }\end{array}$

Bilophila wadsworthia RZATAU (R) aeruginosa, Shewanetia ferroxidans and some (R)

$\operatorname{SRB}(R)$

SRB (F)
S-compound used as substrate for fermentation $(F)$ or terminal electron acceptor in respiratory process (R)

SRB (R) Some strains of Pseudomonas putrefaciens, Acidithiobacilius Enterobacteriaceae: Salmoneila, Protous, Citrobacter, Edwardsielia

$\mathrm{C}_{2} \mathrm{H}_{8} \mathrm{O}_{2} \mathrm{~S}$

Dimethyl -11.3

sulfone

$\mathrm{C}_{3} \mathrm{H}_{9} \mathrm{NO}_{3} \mathrm{~S}$

Homotaurine

$\mathrm{C}_{4} \mathrm{H}_{7} \mathrm{O}_{2} \mathrm{~S}$

Methylthio

propanoate

$\mathrm{CS}_{2}$

Carbondisulice 0.0

\section{$\mathbf{S}^{\circ}$}

Elemental sulfur 8.8

\section{$\mathrm{H}_{2} \mathrm{~S}$}

Sulfide

$\mathrm{CH}_{4} \mathrm{~S}$

Methanethiol

Methanethio

$\mathrm{C}_{5} \mathrm{H}_{10} \mathrm{O}_{2} \mathrm{~S}_{37.5}$

$\mathrm{C}_{2} \mathrm{H}_{6} \mathrm{~S}$

DMS

\section{SR (R) SRB/SR (R)}

Some members of the genus Methanopyrus, Mothanobacterium Methanothermus, and Methanococcus (R) 


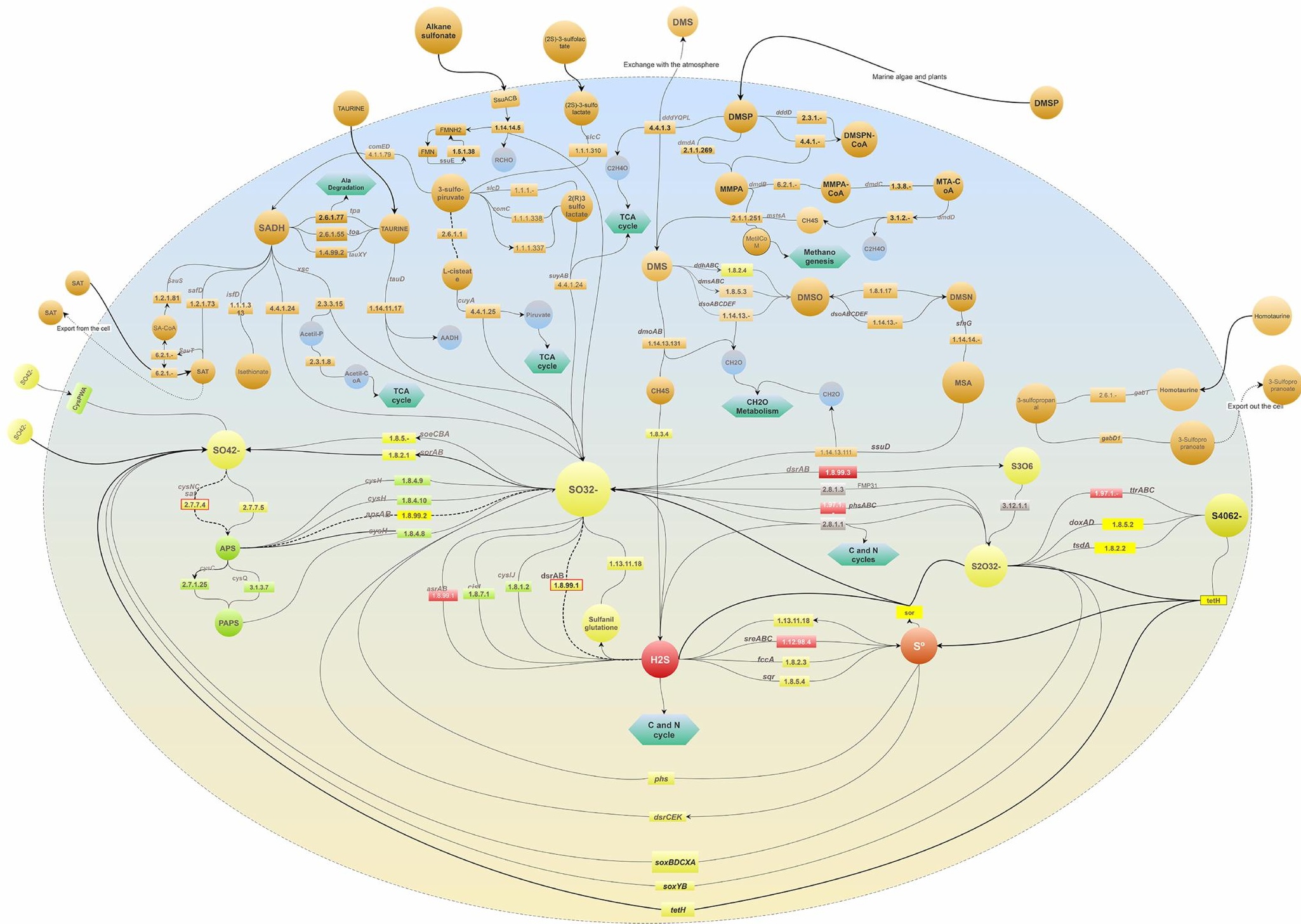




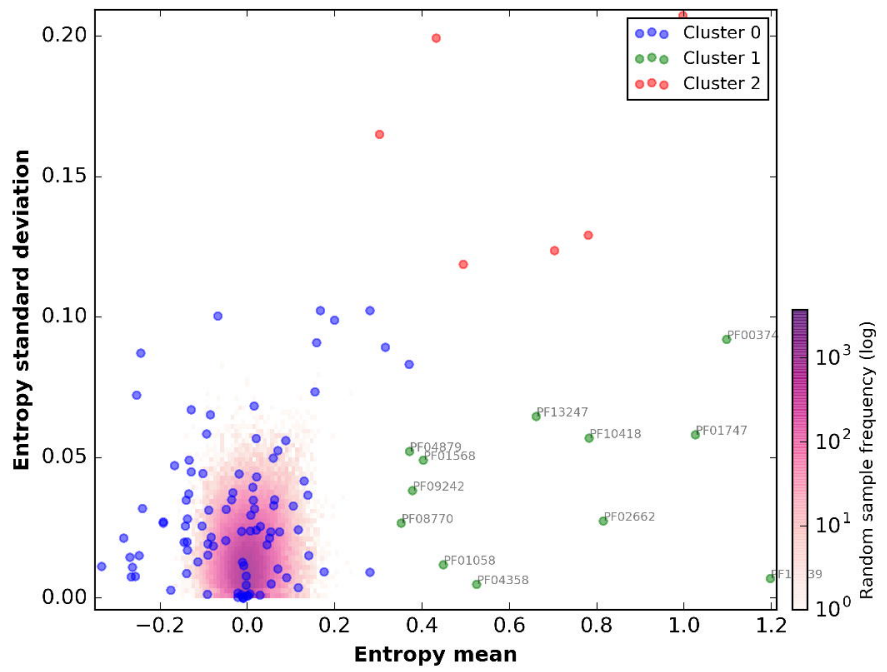




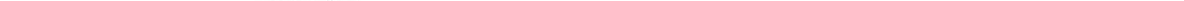



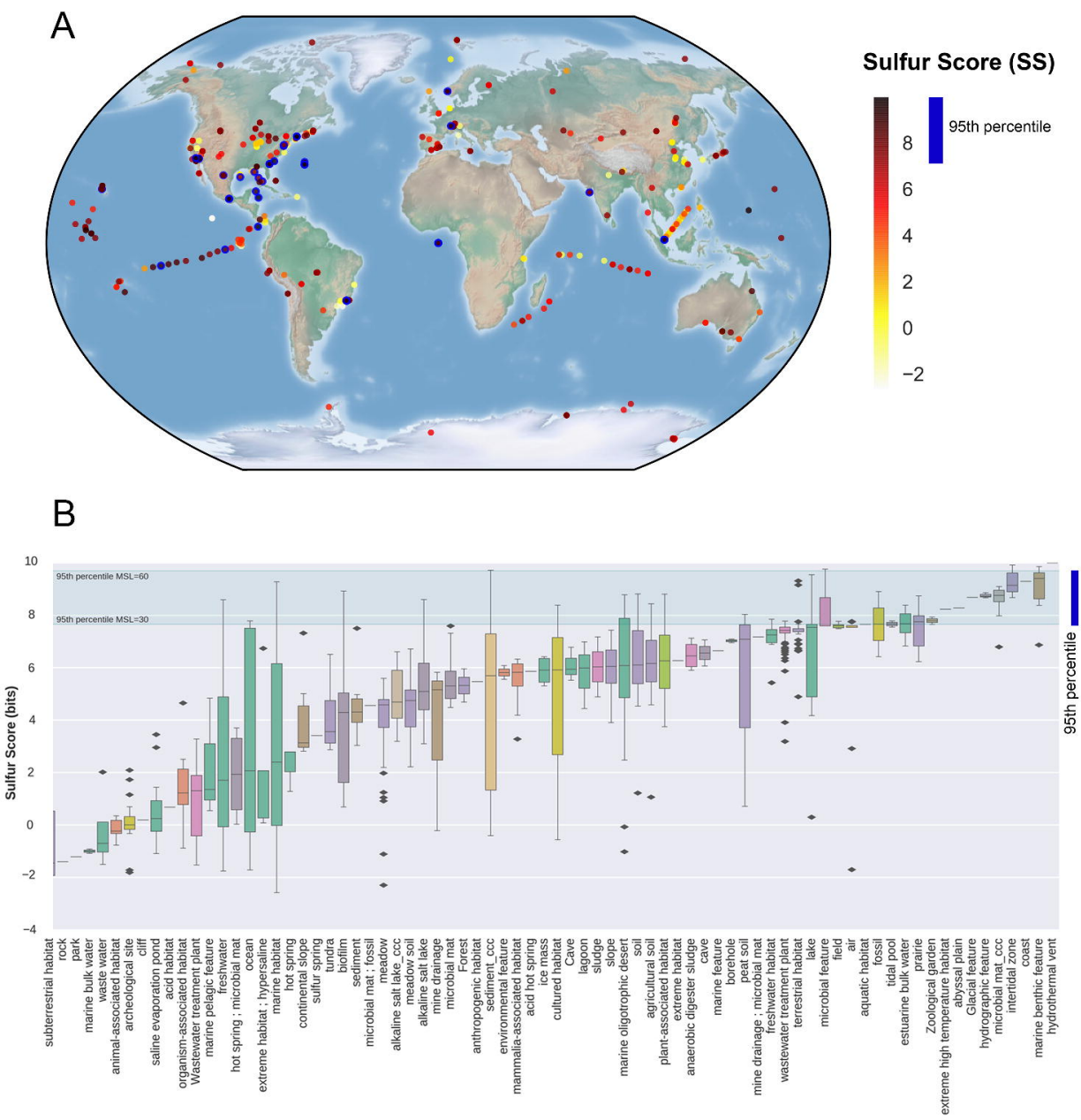

Features
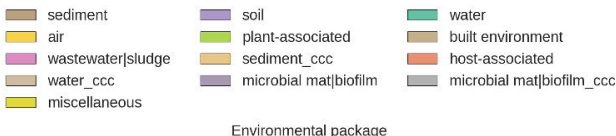